\title{
Interrelations between neurotic syndromes and defense mechanisms
}

\author{
Elena Pilyugina, Ramil Suleymanov* \\ Kazan Innovative University named after V.G. Timiryasov (IEML), Kazan, Russia
}

\begin{abstract}
The article presents a new view on manifestations of neurotic syndromes and their relations to defense mechanisms. The authors consider interrelations between four syndromes - Marilyn syndrome, impostor syndrome, learned helplessness, vernacular Stockholm syndrome) and 20 defense mechanisms, including dissociation, replacement, hypochondria, isolation, regression, passive aggression, etc. It was shown that each of the neurotic syndromes is closely linked to defense mechanisms, which allowed formulating practical recommendations for each subject to solve their problems. Thus, uniting the two phenomena into an interrelated structure forms a diagnostic tool, enabling to use a single feature to reveal a complex of diagnostic parameters, like characteristic personality features, behavior strategies, and anamnesis of child-parent relations; this serves as the basis for predicting the person's behavior, the available and potential resources, and the possible ways of overcoming the current problem. Using such a tool allows significantly simplifying and expediting the diagnostic and therapeutic work of a practical psychologist.
\end{abstract}

\section{Introduction}

The work objective was to research the interrelations between personality defense mechanisms and four widely spread neurotic syndromes - Marilyn syndrome, impostor syndrome, learned helplessness, and vernacular Stockholm syndrome. These syndromes can be considered widely spread, as minimum one of them, more or less expressed, is detected as a deep cause of a current problem in most of a psychologist's clients. As a rule, formation of these syndromes takes place within child-parent relations, in a dysfunctional family [1] and, as consultation practice shows, the specific syndrome depends on the specificity of the family dysfunction; that is, the personality anamnesis includes very specific negative impacts of the family on the personality, which will be considered below.

The Marilyn syndrome is characterized by the following symptoms - lack of love to oneself, up to hatred and disgust, dysmorphophobia, low self-esteem, self-criticism, increased diffidence, perception of oneself as a loser even if socially successful and wellto-do, a fear of loneliness and a sense of needlessness, basic mistrust, etc. The external evidences of the syndrome are obsession with a desire to be in relationships, impetuous

* Corresponding author: souleimanov@ieml.ru 
jealousy, entering the knowingly unpromising relations, preferring unattainable people as partners, friends or bosses, and strong dependence on them, substance use, panic attacks, chronic depressive states, suicidal behavior in extremis [2]. As a rule, the personality anamnesis includes a dysfunctional family with the following main feature - adverse relations with apparent of the opposite sex, namely, the absence or coldness and rejection on the part of a father for a girl and on the part of a mother for a boy. As at that stage of development one parent is the only desired object and the other is the only competitor in the sample, further the perception of one's gender inconsistency and incompetitiveness is transferred to all relationships in general [3-5].

The impostor syndrome is characterized by the following symptoms - perception of oneself as worthless and incompetent in one's activity, constant fear that their worthlessness and incompetence would be unmasked by some more competent authoritative people; anxiety about the inconsistency between their skills and the position occupied or the work done, despite the objective evidences of success; perception of oneself as a child who deceitfully occupied the place of an adult. Also, it is discomfort and devaluation of one's work when praised, as the highest estimation of one's work seems a deceit or a mistake of other people. The syndrome signs are avoidance of increasing payment for one's work, perfectionism, striving to meet all expectations of other people, inability to refuse requests, difficulty in delegating tasks, constraint when presenting one's achievements, etc. [6, 7]. As a rule, the syndrome formation takes place under the following conditions of child-parent relations: overstated parental demands to a child, excessively negative parents' interpretation of a child's mistakes and failures, parents' selfaffirmation on the child's background, disadvantageous comparison of the child with other people, dividing the siblings into more or less preferred, encouraging competition between them, etc. $[8,9]$.

The learned helplessness syndrome is characterized by the following symptoms perceiving any changes as those leading to the situation worsening, lack of confidence in one's abilities and possibility to change the situation for the best, fear of showing initiative, perception of the external factors as dominating and overwhelming. The syndrome's external evidences are the refusal to act in order to change the unfavorable situation even with the resources available, the lack of searching activity, pessimism, negative interpretation of the events, the refusal to control the situation and attributing responsibility for what is going on to the external factors only [10]. The syndrome formation, as a rule, takes place under authoritative or hyperprotective upbringing style under suppressing autonomy, initiative and individuality of a child, contradictory demands of the parents and constant change of their upbringing positions and rules, imposing on the child the ideas of his or her weakness, inability and helplessness, ungrounded and systematic refusal to satisfy the child's desires, cultivation of the child's fears and dangers of the environment, etc. $[11,12]$.

The vernacular Stockholm syndrome is characterized by the following symptoms identification with the partner-aggressor, perception of the partner's aggression toward oneself as justified and normal, perception of the partner's aggression as the manifestation of their power and attractiveness, inclination for codependent relations, inclination for unequal relations, in which one partner is dominating and the other is suppressed. The external signs of the syndrome are the victim's paradoxical behavior in relationships, when the victim justifies the aggressive behavior of the partner, defends him or her against external influences, interprets their aggression as manifestation of love, supports their interests to the detriment of their own, maintain relations with a cruel partner despite the domestic abuse toward the victim which consists in emotional, physical and sexual insults. Also, it is the choice of partners (friends, bosses) inclined to aggression and domination [13-15]. Researchers refer this phenomenon to a variant of the posttraumatic stress 
disorder, because, as a rule, these persons have an anamnesis of a long-term traumatic impact, threatening the very existence of a personality, for example, in the cases when parents systematically committed physical and emotional abuse of a child, limited his or her freedom, interpreted cruel punishment as doing good to a child, and in the cases when there was no equal partnership between parents but domination of one parent over the other, and the child perceived this as a model for partner relationships $[16,17]$.

Both neurotic syndromes and defense mechanisms entail certain stable behavior patterns, thus presenting a high prognostic value for a practicing psychologist. The research topicality lies in the fact that integration of these two phenomena into a single structure form a kind of a diagnostic tool, enabling to use a single feature to reveal a complex of diagnostic parameters, like characteristic personality features, behavior strategies, and anamnesis of child-parent relations; this serves as the basis for predicting the person's behavior, the available and potential resources, and the possible ways of overcoming the current problem. Using such a tool allows significantly simplifying and expediting the diagnostic and therapeutic work of a practical psychologist.

\section{Methodology of research}

The research sample. The total of 200 people took part in consultations, which was a cutoff for data processing. Out of 200 people, 126 people with a minimum one of the studied syndromes were selected. Thus, the experimental sample was 126 subjects, aged from 16 to 56 y.o., including 24 men and 102 women. The research was carried out at Opora Socialpsychological Center in Kazan.

The research methods. We applied a complex theoretical analysis of the studied phenomena, interviews, observations, testing, statistical methods of data processing (Spearman correlation coefficient) using SPSS 23.0 for Windows software.

The personality defense mechanisms were identified with the psychological defense measuring technique (PDMT) by E. R. Pilyugina and R. F. Suleymanov, which measures 20 defense mechanisms, including, by groups of mechanisms: psychotic group (dissociation, replacement, hypochondria, regression, isolation), infantile group (negation, passive aggression, compulsive behavior, projection, substitution), neurotic group (rationalization, avoidance, reaction formation, compensation, omnipotent control), adaptive group (sublimation, altruism, suppression, anticipation, humor) [18].

The presence of a neurotic syndrome was revealed during a consultation interview based on a subject's anamnesis. The criteria for a syndrome presence were symptoms and signs of the syndrome.

\section{Research results}

In a sample of 200 people, the presence of the studied syndromes was identified in 126 people $(63 \%)$, of which 72 subjects had one syndromes, 31 subjects - a set of two syndromes, 15 subjects - a set of three syndromes, 8 subjects - a set of four syndromes (Fig. 1).

Thus, in the sample of 126 people, 208 cases of the studied syndromes were found, including:

- Marilyn syndrome - 62 cases (30\%),

- impostor syndrome - 63 cases $(30 \%)$,

- learned helplessness syndrome - 40 cases $(19 \%)$,

- family-vernacular Stockholm syndrome - 43 cases (21\%). 


\section{The syndromes identified}

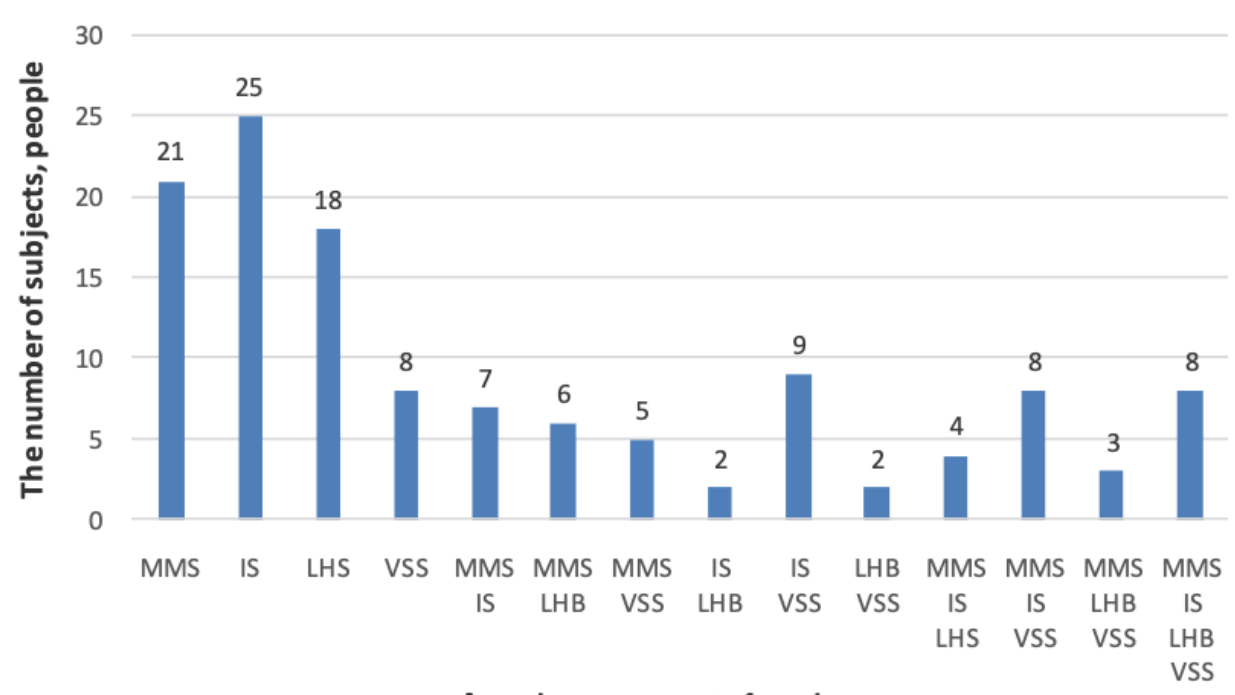

A syndrome or a set of syndromes

Legend. MMS - the Marilyn syndrome, IS - the impostor syndrome, LHS - the learned helpnessness syndrome; VSS - the vennacular Stockholm syndrome

Fig. 1. The number of syndromes and sets of syndromes identified.

In confirmation of the hypothesis, the following correlations between the neurotic syndromes and defense mechanisms were identified (Table 1):

Table 1. Correlations between neurotic syndromes and defense mechanisms.

\begin{tabular}{|c|c|c|c|c|}
\hline \multirow{2}{*}{$\begin{array}{c}\text { Defense } \\
\text { mechanisms }\end{array}$} & \multicolumn{4}{|c|}{ Neurotic syndrome } \\
\hline & $\begin{array}{l}\text { Marilyn } \\
\text { syndrome }\end{array}$ & $\begin{array}{l}\text { Impostor } \\
\text { syndrome }\end{array}$ & $\begin{array}{c}\text { Learned } \\
\text { helplessness } \\
\text { syndrome }\end{array}$ & $\begin{array}{l}\text { Vernacular } \\
\text { Stockholm } \\
\text { syndrome }\end{array}$ \\
\hline Dissociation & .093 & .128 & .014 & $.532^{* *}$ \\
\hline Regression & .090 & -.035 & $.347^{* *}$ & .014 \\
\hline Hypochondria & $.478^{* *}$ & -.106 & -.066 & .100 \\
\hline Isolation & .109 & $.337^{* *}$ & -.039 & $.219^{*}$ \\
\hline Replacement & $.210^{*}$ & .124 & .011 & $.431^{* *}$ \\
\hline Substitution & .152 & .026 & .128 & .029 \\
\hline Projection & $.202^{*}$ & .044 & -.038 & $.222^{*}$ \\
\hline Compulsive behavior & $.375^{* *}$ & -.099 & -.001 & .156 \\
\hline Passive aggression & $.209^{*}$ & -.056 & $.423^{* *}$ & .102 \\
\hline Negation & $-.236^{* *}$ & -.094 & $.380^{* *}$ & -.093 \\
\hline
\end{tabular}




Continuation of table 1.
\begin{tabular}{|c|c|c|c|c|} 
Rationalization & .053 & $.433^{* *}$ & -.080 & .110 \\
\hline Avoidance & .081 & $.314^{* *}$ & .064 & $.326^{* *}$ \\
\hline Reaction formation & $.244^{* *}$ & -.015 & .155 & $.359^{* *}$ \\
\hline Compensation & $.400^{* *}$ & -.025 & -.010 & .080 \\
\hline Omnipotent control & .167 & .122 & .062 & .083 \\
\hline Sublimation & .014 & $.415^{* *}$ & -.114 & .119 \\
\hline Altruism & .107 & .089 & -.106 & $.364^{* *}$ \\
\hline Impulse suppression & .016 & .096 & .050 & $.337^{* *}$ \\
\hline Anticipation & .128 & $.349^{* *}$ & $-.241^{* *}$ & .141 \\
\hline Humor & .047 & .048 & -.026 & $.222^{*}$ \\
\hline
\end{tabular}

\section{Discussion of the results}

The correlations identified lead to the following characteristic of a personality with a Marilyn syndrome:

- with the reactive formation defense mechanism $(\mathrm{r}=0.244$ at $\mathrm{p} \leq 0.01)$, which consists in demonstrating the socially-approved behavior in order to conceal their actual desires, not approved by the society [19]. A personality with a Marilyn syndrome tends to demonstrate oneself as good and "proper", as it also helps to attract more social attention and support.

- with the hypochondria defense mechanism $(\mathrm{r}=0.478$ at $\mathrm{p} \leq 0.01)$ shows that these persons tend to fall ill when responsibility and initiative should be demonstrated [20]. Formation of this mechanism originates from child-parent relations, when falling ill helped a child to get attention and care from their relatives and/or provided an "indulgence" against the committed misdeeds. An escape to psychosomatic diseases allows a person to attract the desired attention and care from the society.

- with the replacement defense mechanism $(\mathrm{r}=0.210$ at $\mathrm{p} \leq 0.05)$ demonstrates that such persons adhere to a defense of the most destructive psychotic level, which is formed under a threat to individual existence [21]. For example, it can be a categorical reluctance of the parents to have this child. The subjects with this syndrome rather often mention that their parents wanted to terminate their pregnancy.

- with the projection defense mechanism $(\mathrm{r}=0.202$ at $\mathrm{p} \leq 0.05)$ shows that the person is suspicious and tends to attribute their own negative features to others [22].

- with the compensation defense mechanism $(\mathrm{r}=0.400$ at $\mathrm{p} \leq 0.01)$, which allows distracting from anxiety due to the alleged or real drawbacks with the help of some status achievements - material acquisitions, appearance improvements, and everything that demonstrates success in the society [23]; it gives a personality such features as envy, arrogance, boastfulness. The person is characterized by striving for prestige, increased ambitions and unsteady self-esteem depending on external factors.

- reverse correlation with the negation defense mechanism $(\mathrm{r}=-0.236$ at $\mathrm{p} \leq 0.01)$, the essence of which lies in ignoring the anxiety factors and being excessively careless [24]; it shows that people with this syndrome are, on the contrary, fixed on anxiety aspects and are excessively suspicious. They constantly compare themselves with others against their own 
benefit, take hard their slightest drawbacks, and exaggerate them to a maximum in their interpretations.

The revealed correlations yield the following characteristic of a personality with the impostor syndrome:

- with the isolation defense mechanism $(\mathrm{r}=0.337$ at $\mathrm{p} \leq 0.01)$ makes a person emotionally reserved, closed, lacking response to significant events [25]. S. Freud thought that with isolation an individual puts oneself into an active position instead of a passive one, while staging one's own disappearance in response to a traumatic event [26]. Isolation allows sensitive people to detach their sensitivity from themselves, switch off the emotional perception and experiencing of a traumatic situation;

- with the rationalization defense mechanism ( $\mathrm{r}=0.433$ at $\mathrm{p} \leq 0.01$ ), when a person uses substantiation and pseudo-reasonable explanations for one's behavior [27], makes a person with the impostor syndrome painfully perceive his or her failure and mistakes. Since childhood, these persons were made increased demands of in terms of reasonableness, weighed behavior and high results in all spheres, so they do not forgive their own mistakes and a search for self-excuses is their urgent demand in case of the least failure;

- with the avoidance defense mechanism $(\mathrm{r}=0.315$ at $\mathrm{p} \leq 0.01)$ makes a person painfully perceive his or her failure [28]. They thoroughly avoid competition in the cases when then have no guarantee of winning, and reject initiative every time they are not sure in their decision. If such a person cannot be the best in some activity, he or she would refuse that activity, not to subject their self-esteem to risks compared with more successful competitors;

- with the sublimation defense mechanism $(\mathrm{r}=0.415$ at $\mathrm{p} \leq 0.01)$ makes a person keen on his or her occupation and purposeful. The essence of his mechanism is transference of sexual and aggressive energy into a socially acceptable and constructive plane - into creative, sport, scientific or other socially useful activity [29]. The person would pose complex tasks and goals for oneself, which would require using and developing a lot of resources, like will power, self-control, diligence, persistence, thoughtfulness, creativity, etc. That is why persons with the impostor syndrome are often very competent specialists achieving objective success in their activity;

- with the anticipation defense mechanism $(\mathrm{r}=0.349$ at $\mathrm{p} \leq 0.01)$ leads to the person underestimating his or her abilities but, as a rule, overestimating hardships and dangers; that is why such persons are very cautious and mentally rehearse all the variants of the coming event, which allows them to be more prepared for the future and suppress their excessive diffidence [30].

The correlations found provide the following characteristic of a personality with the learned helplessness syndrome:

- with the regression defense mechanism $(\mathrm{r}=0.347$ at $\mathrm{p} \leq 0.01)$ makes a person infantile, whining, inclined for complaints, weal, vulnerable, helpless, striving for guidance on the part of others [31].

- with the passive aggression defense mechanism $(\mathrm{r}=0.423$ at $\mathrm{p} \leq 0.01)$ makes a person inclined for sabotage, ignoring and forgetting their duties, shifting responsibility to others $[32,33]$. The sources of passive aggression lie in the learned ability to suppress one's feelings and conceal one's wishes, when a person gets used to expressing his or her discontent indirectly, without taking cardinal steps for changing the situation.

- with the negation defense mechanism $(\mathrm{r}=0.380$ at $\mathrm{p} \leq 0.01)$ makes a person evade from the traumatizing reality and tend to avoid new information, which allows the person to preserve the situation unchanged, staying immersed into their illusions [34].

- reverse correlation with the anticipation defense mechanism $(r=-0.241$ at $\mathrm{p} \leq 0.01)$ indicates that a person does not attempt to prepare or the future by mentally rehearsing the 
possible variants of the course of events, as this process is too traumatic for him or her, thus, the person tries to avoid any, even hypothetical, worries [35].

The identified correlations lead to the following characteristic of a personality with the vernacular Stockholm syndrome:

- with the dissociation defense mechanism $(\mathrm{r}=0.532$ at $\mathrm{p} \leq 0.01)$ and replacement defense mechanisms $(\mathrm{r}=0.431$ at $\mathrm{p} \leq 0.01)$ shows that a person with the vernacular Stockholm syndrome uses the most in-depth, psychophysiology level defense, when a personality adheres to ignoring or forgetting events, splitting of consciousness [36, 37]. Such defense develops most often under the most traumatic conditions of ontogenesis, when the very existence of an individual was threatened, and it makes the most destructive impact on a personality and worsens social adaptation $[38,39]$.

- with the avoidance defense mechanism $(\mathrm{r}=0.326$ at $\mathrm{p} \leq 0.01)$ makes a person painfully perceive failure, when he or she rejects the initiative every time he or she is not confident on success. Such a person is always ready to yield initiative.

- with the reactive formation defense mechanism $(\mathrm{r}=0.359$ at $\mathrm{p} \leq 0.01)$ makes a person strive for the "proper", socially approved behavior to the detriment of their true but not socially approved desires [40]. Such persons have increased sense of duty and responsibility, they are easily imposed a sense of guilt, which is one of the factors why they stay close to their tyrant partners.

- with the altruism defense mechanism $(\mathrm{r}=0.364$ at $\mathrm{p} \leq 0.01)$ gives a person a passion for charity, a desire to help and rescue. Altruism protects a person against realization of his or her own need for care, bringing pleasure of satisfying other people's needs [41].

- with the impulse suppression defense mechanism $(\mathrm{r}=0.337$ at $\mathrm{p} \leq 0.01)$ gives a person restraint as a characteristic feature. With a will effort, the person postpones realization of a problem till the moment he or she is psychologically prepared to face an unpleasant fact [39].

The results obtained allow stating that there exist correlations between neurotic syndromes with character accentuations and personality defense mechanisms. In particular, the revealed correlations between neurotic syndromes and psychological defenses allow proposing specific practical recommendations. Thus, the Marilyn syndrome shows direct correlations with such defense mechanisms as reaction formation, hypochondria, replacement, projection, compensation, and a reverse correlation with negation. Practical recommendations include focusing on elaborating adequate self-estimation, developing will power and adherence to healthy lifestyle.

The impostor syndrome directly correlates with such defense mechanisms as isolation, rationalization, avoidance, sublimation, and anticipation. Among the practical recommendations we can propose focusing on increasing one's self-confidence by fixation on actual achievements, developing spontaneity in behavior, developing creativity, communicativeness and understanding of other people's motives and feelings.

The learned helplessness syndrome shows direct correlations with such defense mechanisms as regression, passive aggression, negation, and a reverse correlation with anticipation. Practical recommendations include working with the locus of control and increasing the sense of responsibility for what is happening, and focusing on a more mature and weighed estimation of what is happening.

The vernacular Stockholm syndrome has direct correlations with such defense mechanisms as dissociation, replacement, avoidance, reaction formation, altruism, and impulse suppression. Practical recommendations are focusing on increasing self-estimation, self-confidence and healthy egocentrism, stimulating expressivity, in-depth psychotherapy of psychotraumas. 


\section{Conclusion}

Summarizing the above, we should point out that each of the neurotic syndromes has close connections with defense mechanisms, which allowed formulating practical recommendations for each subject to solve their problems. Thus, uniting the two phenomena into an interrelated structure forms a diagnostic tool, enabling to use a single feature to reveal a complex of diagnostic parameters, like characteristic personality features, behavior strategies, and anamnesis of child-parent relations; this serves as the basis for predicting the person's behavior, the available and potential resources, and the possible ways of overcoming the current problem. Using such a tool allows significantly simplifying and expediting the diagnostic and therapeutic work of a practical psychologist.

\section{Acknowledgment}

The article was prepared with the financial support of Kazan Innovative University named after V. G. Timiryasov.

\section{References}

1. S. M. Flores, G. A. Salum, G. G. Manfro, Dysfunctional family environments and childhood psychopathology: the role of psychiatric comorbidity, Trends in Psychiatry and Psychotherapy, 36, 147-151 (2014). Access mode: https://doi.org/10.1590/22376089-2014-0003

2. E. I. Macavoy, Lovesick: The Marilyn Syndrome (1991)

3. A. A. Ali, F. S. Daoud, Early father-daughter relationship and demographic determinants of spousal marital satisfaction, Psychology research and behavior management, 9, 61 (2016). Access mode: https://doi.org/10.2147/PRBM.S96345

4. B. J. Ellis, G. L. Schlomer, E. H. Tilley, E. A. Butler, Impact of fathers on risky sexual behavior in daughters: A genetically and environmentally controlled sibling study, Development and psychopathology, 24, 317-332 (2012). Access mode: https://doi.org/10.1017/S095457941100085X

5. L. Nielsen, Father-daughter relationships: Contemporary research and issues (2019). Access mode: https://doi.org/10.4324/9780429279133

6. S. Rohrmann, M. N. Bechtoldt, M. Leonhardt, Validation of the impostor phenomenon among managers, Frontiers in psychology, 7, 821 (2016). Access mode: https://doi.org/10.3389/fpsyg.2016.00821

7. N. Schubert, A. Bowker, Examining the impostor phenomenon in relation to selfesteem level and self-esteem instability, Current Psychology, 38, 749-755 (2019). Access mode: https://doi.org/10.1007/s12144-017-9650-4

8. E. D. Cohen, W. R. McConnell, Fear of fraudulence: graduate school program environments and the impostor phenomenon, The Sociological Quarterly, 60, 457-478 (2016). Access mode: https://doi.org/10.1080/00380253.2019.1580552

9. K. K. Mak, S. Kleitman, M. J. Abbott, Impostor phenomenon measurement scales: a systematic review, Frontiers in psychology, 10, 671 (2019). Access mode: https://doi.org/10.3389/fpsyg.2019.00671

10. F. Lieder, N. D. Goodman, Q. J. Huys, Learned helplessness and generalization, Proceedings of the annual meeting of the cognitive science society, 35 (2013) 
11. M. Mikulincer, Human learned helplessness: A coping perspective, Springer Science \& Business Media (2013)

12. S. Nuvvula, Learned helplessness, Contemporary clinical dentistry, 7, 426 (2016). Access mode: https://doi.org/10.4103/0976-237X.194124

13. M. Namnyak, N. Tufton, R. Szekely, M. Toal, S. Worboys, E. L. Sampson, 'Stockholm syndrome': psychiatric diagnosis or urban myth? Acta Psychiatrica Scandinavica, 117, 4-11 (2008)

14. C. Bachand, N. Djak, Stockholm syndrome in athletics. A Paradox, Children Australia, 43, 175-180 (2018). Access mode: https://doi.org/10.1017/cha.2018.31

15. M. H. Logan, Stockholm syndrome: held hostage by the one you love, Violence and gender, 5, 67-69 (2018). Access mode: https://doi.org/10.1089/vio.2017.0076

16. M. Adorjan, T. Christensen, B. Kelly, D. Pawluch, Stockholm syndrome as vernacular resource, The Sociological Quarterly, 53, 454-474 (2012). Access mode: https://doi.org/10.1111/j.1533-8525.2012.01241.x

17. C. Rahme, C. Haddad, M. Akel, C. Khoury, H. Obeid, S. Obeid, S. Hallit, Does Stockholm syndrome exist in Lebanon? Results of a cross-sectional study considering the factors associated with violence against women in a Lebanese representative sample, Journal of interpersonal violence (2020). Access mode: https://doi.org/10.1177/0886260519897337

18. E. R. Pilyugina, R. F. Suleymanov, Methodology of measuring psychological defense, Experimental psychology, 13, 194-209 (2020). Access mode: https://doi.org/10.17759/exppsy.2020130213

19. S. Freud, The ego and the mechanisms of defence (2018). Access mode: https://doi.org/10.4324/9780429481550

20. H. A. Thorner, Three Defences Against Inner Persecution: Examination Anxiety, Depersonalization and Hypochondria, New Directions in Psycho-Analysis, 282-306 (2018).

21. R. D. Hinshelwood, Repression and splitting: Towards a method of conceptual comparison, The International Journal of Psychoanalysis, 89, 503-521 (2008). Access mode: https://doi.org/10.1111/j.1745-8315.2008.00055.x

22. E. Cleavely, Relationships: interaction, defences, and transformation, in: Psychotherapy with couples, 55-69 (2018). Access mode: https://doi.org/10.4324/9780429479298-7

23. S. S. Fehr, Resistance and Self-Protection: Ego Defense Mechanisms and the Process of Adjustment, Introduction to Group Therapy, 83-104 (2018). Access mode: https://doi.org/10.4324/9781351007481-8

24. P. Cramer, Understanding defense mechanisms, Psychodynamic Psychiatry, 43, 523552 (2015). Access mode: https://doi.org/10.1521/pdps.2015.43.4.523

25. T. Strandholm, O. Kiviruusu, L. Karlsson, J. Miettunen, M. Marttunen, Defense mechanisms in adolescence as predictors of adult personality disorders, The Journal of nervous and mental disease, 204, 349-354 (2016). Access mode: https://doi.org/10.1097/NMD.0000000000000477

26. G. E. Vaillant, The historical origins and future potential of Sigmund Freud's concept of the mechanisms of defence, International Review of Psycho-Analysis, 19, 35-50 (1992) 
27. M. Knoll, C. J. Starrs, J. C. Perry, Rationalization (defense mechanism), Encyclopedia of personality and individual differences, 4301-4305 (2020). Access mode: https://doi.org/10.1007/978-3-319-24612-3_1419

28. M. D. Berzonsky, A. Kinney, Identity processing style and depression: The mediational role of experiential avoidance and self-regulation, Identity, 19, 83-97 (2019). Access mode: https://doi.org/10.1080/15283488.2019.1567341

29. S. Wright, B. Crewe, S. Hulley, Suppression, denial, sublimation: Defending against the initial pains of very long life sentences, Theoretical Criminology, 21, 225-246 (2017). Access mode: https://doi.org/10.1177/1362480616643581

30. G. E. Vaillant, Adaptive mental mechanisms: Their role in a positive psychology, American psychologist, 55 (1), 89 - 98 (2000). Access mode: https://doi.org/10.1037/0003-066X.55.1.89

31. H. Weinberg, Regression in the group revisited, Group, 30 (1), 37-53 (2006)

32. C. G. Schanz, M. Equit, S. K. Schäfer, M. Käfer, H. K. Mattheus, T. Michael, Development and psychometric properties of the test of passive aggression, Frontiers in psychology, 12 (2021). Access mode: https://doi.org/10.3389/fpsyg.2021.579183

33. F. Mesgarian, P. Azad Fallah, H. Farahani, N. Ghorbani, Object Relations and defense mechanisms in social anxiety (2017)

34. P. Cramer, The development of defense mechanisms: Theory, research, and assessment (2012)

35. J. A. Metzger, Adaptive defense mechanisms: function and transcendence, Journal of clinical psychology, 70, 478-488 (2014). Access mode: https://doi.org/10.1002/jclp.22091

36. S. D. Purcell, Dissociation or Hypnoid Phenomenon? Journal of the American Psychoanalytic Association, 68, 889-906 (2020). Access mode: https://doi.org/10.1177/0003065120967260

37. U. Kramer, Y. de Roten, J. C. Perry, J-N. Despland, Beyond splitting: Observer-rated defense mechanisms in borderline personality disorder, Psychoanalytic Psychology, 30, 3-15 (2013). Access mode: https://doi.org/10.1037/a0029463

38. J. C. Perry, M. D. Presniak, T. R. Olson, Defense mechanisms in schizotypal, borderline, antisocial, and narcissistic personality disorders, Psychiatry: Interpersonal \& Biological Processes, 76, 32-52 (2013). Access mode: https://doi.org/10.1521/psyc.2013.76.1.32

39. S. Boag, Repression, suppression, and conscious awareness, Psychoanalytic Psychology, 27, 164 (2010). Access mode: https://doi.org/10.1037/a0019416

40. N. McWilliams, Psychoanalytic diagnosis: Understanding personality structure in the clinical process (2011)

41. S. Sun, From defensive altruism to pathological altruism, SAGE Open, 8, 1-8 (2018). Access mode: https://doi.org/10.1177/2158244018782585 